(2) Open Access Full Text Article

\title{
Assessment of suicidality in children and adolescents with diagnosis of high functioning autism spectrum disorder in a Turkish clinical sample
}

This article was published in the following Dove Press journal:

Neuropsychiatric Disease and Treatment

II November 2016

Number of times this article has been viewed

\author{
Sevcan Karakoç Demirkaya' \\ Mustafa Deniz \\ Tutkunkardaș² \\ Nahit Motavalli Mukaddes ${ }^{3}$ \\ 'Department of Child Psychiatry, \\ Adnan Menderes University School \\ of Medicine, Aydin, ${ }^{2}$ Department of \\ Child Psychiatry, Istanbul School of \\ Medicine, Istanbul University, Istanbul, \\ ${ }^{3}$ Istanbul Institute of Child and \\ Adolescent Psychiatry, Istanbul, Turkey
}

Correspondence: Nahit Motavalli Mukaddes

Istanbul Institute of Child and Adolescent Psychiatry, Valikonagi caddesi,

No 106.D: 13 Nisantasi, Istanbul, Turkey

Tel +902122349207

Fax +902122349208

Emailnmotavalli@yahoo.com
Objectives: Considering that suicide is one of the most common reasons of adolescent death worldwide, there is a lack of clinical awareness on suicidal behaviors of children and adolescents with autism spectrum disorder (ASD). The present study aims to assess the rate of suicidality (suicidal ideation, behaviors and attempts) and associated risk factors for suicidality in high functioning ASD.

Methods: Medical records of 55 adolescents (six girls, 49 boys), aged between 7-20 years, with diagnosis of ASD were reviewed. The participants were all able to speak fluently and had no significant limitations in intellectual functioning. Clinical assessment of participants was carried out on the basis of Diagnostic and Statistical Manual of Mental Disorders 4th Edition, Text Revision criteria and Schedule for Affective Disorders and Schizophrenia for School-Age Children-Present and Lifetime Version. Eskin's Suicide Screening Questionnaire and sociodemographic data form including detailed history of suicidal behaviors were used. The study group was also divided into suicidal and non-suicidal groups for the purpose of comparing the results.

Results: The rate of suicidal behaviors was $29 \%$ and suicide attempt was $12.7 \%$. Types of suicidality were behaviors (43.7\%), thoughts (37.5\%), and verbal declarations (18.7\%). A number of bizarre acts were recorded. Rates of comorbid psychiatric disorders such as mood disorders, anxiety disorders and disruptive behaviors were $23.6 \%, 43.6 \%$ and $65.4 \%$ respectively. Groups with the psychotic features, positive family history for suicidal behaviors and completed suicide showed more suicidality than the non-suicidal group.

Conclusion: Consistent with the previous findings, rate of suicidality is higher in individuals with ASD. The type of suicidal behaviors showed some differences compared to typically developing individuals. The presence of psychotic features and positive family history for suicidality may be risk factors for suicidality in children and adolescents with ASD. To prevent suicide and implement protective health care systems, identifying the population at risk is crucial.

Keywords: autism, adolescent, child, suicidal attempt, suicidal ideation

\section{Introduction}

Autism spectrum disorders (ASDs) are neurodevelopmental disorders characterized by persistent impairment in social communication and social interactions and restricted, repetitive patterns of behavior, interest and activities. ${ }^{1}$ Whilst clinical interest groups and research in comorbid psychiatric disorders with ASD have firmly increased in recent years, there are still few reliable studies and major lack of clinical awareness on suicidal behavior in this group. However, suicide is one of the most common causes of adolescent death worldwide..$^{2-7}$ This is despite the fact that lifetime prevalence of 
nonlethal suicidal behaviors, including ideation, plan and attempt, is relatively higher in adolescents. ${ }^{8}$

The earliest study ever reported for suicide in ASD was authored by Hardan and Stahl, where a heterogeneous group of 233 individuals with developmental disabilities were examined for variables relevant to suicidality. ${ }^{9}$ Among their sample, a subgroup of 63 individuals was reported to display pervasive developmental disorders (PDDs). Suicidality was observed in seven individuals with diagnosis of autistic disorder (AD). On closer scrutiny, it was outlined that impulsivity, hyperactivity, sadness, poor concentration, and aggression were closely linked with suicide in subjects with developmental disabilities. In another related study, Mandell et al reported suicidality in youth with autism and history of physical and sexual abuse. ${ }^{10}$ Additionally, Mukaddes and Fateh conducted a study in respect of psychiatric comorbidity on 37 individuals with Asperger's syndrome (AS) where the rate of suicidality was identified to be as high as $42 \%$ among adolescents with AS. ${ }^{11}$ Another key conclusion drawn in that study was that suicide most consistently correlated with major depressive disorder and anxiety. Interestingly, it was demonstrated that all female adolescents with AS suffered from suicidal ideas and/or suicide attempts. ${ }^{11}$ Another study conducted on AS cases is Cassidy et al's study consisting of 374 adults aged $17-67$ years. They showed that the cases with comorbid depression were more likely to report suicidal ideation, suicide plans or attempts. ${ }^{12}$

In addition to the studies outlined above, in a recent study by Kato et al where 587 suicidal adult patients were investigated, ASD was identified in $7.3 \%$ of them. ${ }^{13}$ Therefore, they suggested to screen for diagnosis of ASD in all referrals of suicidality. Mayes et al assessed the suicidality in 791 children with diagnosis of ASD. Based on mothers' reports, suicidality in this population was 28 times more than in typically developing children. Proposed risk factors are as follows: being male, aged 10 or older, Black or Hispanic and having lower socioeconomic status. ${ }^{14}$ Depression and trauma are other documented risk factors for suicidality in youth with ASD. ${ }^{15}$

Recently, two reviews were published on this topic. ${ }^{16,17}$ First Hannan and Taylor's review of four different studies revealed that prevalence of suicidality among adolescents and young adults with ASD varied from $7 \%$ to $42 \% .{ }^{16}$ It was evidenced that the risk of documented suicide was related to many factors such as age, gender, ethnicity, additional psychiatric disorder, family history for psychiatric disorder, family history for suicide, substance abuse, interpersonal problems, bullying, abuse, social isolation, and low selfesteem. The second review study on suicide literature, undertaken by Segers and Rawana, provided harmonized opinions on ten different studies where their observations overlapped with the former review to a certain extent. Segers and Rawana reported that suicidality was a common problem in subjects with diagnosis of ASD with varying rates from $10 \%$ to $50 \%$ of the study samples. They also identified the risk factors that may have an impact on suicidality including peer victimization, behavioral problems, being male, being from low socioeconomic class and education. ${ }^{17}$

Through a comprehensive review of the studies in this field set out above, it appears that the majority of these studies included late adolescents and adults, and a number of them provided information regarding suicide on the basis of medical records rather than direct examination of patients, and also most of these studies had small sample sizes. We therefore conducted a chart review study to assess suicidality in clinically referred children and adolescents with high functioning ASD with regards to clinical examination. This represents the first study associated with suicidality in ASD in Turkey. With this purpose our aims were as follows:

- to assess, in a tertiary clinical setting, the prevalence of suicidal behaviors in a sample of children and adolescents with high functioning ASD;

- to evaluate the associated risk factors associated with suicidality; and

- to identify the characteristics of suicidal ideation and behaviors.

\section{Methods}

\section{Participants}

The patients of the Autism Clinic of Child and Adolescent Psychiatry Department of the university hospital participated in this study, and were all followed-up for a period of 1-15 years. They were diagnosed and assessed by at least two different (one junior and one senior expert in the field) child psychiatry specialists both on admission and during follow-up processes. They were followed-up routinely and the subjects with high functioning ASD were also screened for suicidal behaviors as a routine procedure during control visits.

The following inclusion criteria were applied during review of the charts:

- capability of reading, writing and speaking;

- no intellectual disability (IQ $\geq 70$ ) revealed by any IQ test appropriate for the age;

- no history of chronic neurological or physical disorder;

- presence of data about suicidality.

\section{Assessment}

All medical charts of the children with diagnosis of ASD were evaluated but only 55 of the medical records of the individuals who were eligible for the inclusion criteria were reviewed 
by the study team experienced in ASD. In the absence of the Autism Diagnostic Interview in our country, and as the recruitment process of the study was undertaken before the publication of Diagnostic and Statistical Manual of Mental Disorders (DSM)-5, the diagnoses were implemented on the basis of DSM-IV-TR criteria and clinical observations by the authors, three experts of ASD who have at least 10 years of experience in the field. ${ }^{1,18}$

Ethics approval was obtained from the Institutional Review Board of Istanbul University. It is imperative to note that the study was carried out according to the Declaration of Helsinki Human Rights and thereby written informed consents were granted directly by the parents of the participants to use and present the participants' data in this study when they were filling out the data forms in routine visits.

\section{Measurements}

Sociodemographic data form: this was produced by the authors and used routinely in the clinic. It was administered by the clinicians and based on the parent report and direct clinical observation. This form was composed of a detailed developmental history, as well as history of behavioral, emotional and physical problems if present. Detailed medical history (drugs, comorbid diseases, hospitalizations, emergency visits), family history of suicidal behaviors and attempts, alcohol-substance use disorder and other psychiatric disorders, aggressive behaviors of the patients toward others and self, and presence of suicidal behaviors, attempts and declarations were recorded in this form.

Two principal measurements were also applied routinely to the follow-up patients:

- Schedule for Affective Disorders and Schizophrenia for School-Age Children-Present and Lifetime Version (K-SADS-PL): this interview form is widely used for assessment of psychiatric disorder in patients aged between 6 and 18. ${ }^{19}$ The validation and reliability of the Turkish version were affirmed by Gokler et al. ${ }^{20}$

- Eskin's Suicide Screening Questionnaire: Eskin's Suicide Screening Questionnaire contains five yes/no questions regarding suicidal ideation and behavior. In particular these questions are:

1. Have you ever thought of suicide in your life?

2. Have you thought of suicide within the last 12 months?

3. Do you now consider suicide?

4. Have you ever attempted suicide?

5. Have you attempted suicide within the last 12 months?

The participants were regarded as suicidal if they provided a positive, ie, "yes", answer to one of the first three questions, and similarly, in case of a positive answer to the last two questions, they were regarded as having attempted suicide. ${ }^{21}$ This questionnaire was administered by the clinicians and further parent reports were obtained to gather the right information.

\section{Statistical analyses}

Data analysis was conducted by way of computer based statistics software (SPSS 17.0, SPSS Inc., Chicago, IL, USA). Through this software, descriptive statistics including the means and ratio intervals were calculated. The study groups were primarily divided into two subgroups according to the presence of suicidality. Qualitative variables such as gender and history between independent groups were compared with chi-square $\left(X^{2}\right)$ tests. Pearson, Fisher's Exact and McNemar chi-square test were used to compare quantitative variables (such as ratio of comorbid disorders) between two independent groups.

\section{Results}

The DSM-IV diagnoses in the study group were AS ( $n=26)$, AD $(n=24)$, PDD not otherwise specified (PDD-NOS) $(n=5)$. The group included 18 children and 37 adolescents ( $\geq 12$ years old) aged between 7 and 20 (mean: 13.56 \pm 2.9 ). Wechsler Intelligence Scale for Children-Revised form (WISCR) was administered to all children routinely. However, if the child failed to respond to the test for any reason, the other tests were applied in our clinical practice. In this study WISCR ( $n=31)$, Cattell IQ $(n=9)$ and Stanford Binet tests $(n=15)$ were applied to the participants. Mean total IQ score was $93.53 \pm 14.52$ ( $\min -\max ; 70-126$ ).

Our findings as to the rate of suicidality, type of suicidal behavior and risk factors are outlined as follows.

\section{Rate of suicidality}

Suicidality was observed in 16 individuals in our group which accounts for a rate of suicide of $29 \%$. Among the suicidal ones, seven individuals had the diagnosis of AD, eight had AS, and an individual had PDD-NOS.

\section{The severity of suicidality}

History of suicidality was broadly classified as behaviors (43.7\%), thoughts (37.5\%), and verbal declarations (18.7\%). Suicidal behaviors were observed among seven individuals within the suicidal group and the remaining nine individuals had suicidal ideation. This corresponds to $12.7 \%$ and $16.3 \%$ of the whole sample, respectively. Subjects with ASD are known as having less abstract and logical thinking. Consistent with this assumption, a number of bizarre acts were recorded. 
To illustrate, a patient not only stuffed his nose with paper, but also drank cologne. Similar acts such as thrusting own face into a pillow and ingesting his/her entire daily dose of medications at one time were recorded. None of the patients had hospitalizations due to their attempts. All suicide attempters $(n=7)$ were admitted to our child psychiatry clinic as an emergency visit, but the others with suicidal ideations $(n=6)$ or declarations $(n=3)$ sought no emergency medical help.

\section{Risk factors}

Two groups were distinguished as suicidal and non-suicidal groups. Table 1 provides a list of suicidality risk factors assessed in this study. From a statistics point of view, no significant difference was identified in terms of age, gender, subtypes of PDD, parental loss or divorce, and family history of substance abuse. However, there were statistical significances between two groups in connection with positive family history for completed suicide and positive family history for suicidal behaviors.

It is also noteworthy that comorbid psychiatric disorders were common in our group: the rates of mood disorders, anxiety disorders and disruptive behaviors were $23.6 \%, 43.6 \%$ and $65.4 \%$ respectively. In particular, attention deficit hyperactivity disorder was identified as the most common additional diagnosis. Of all psychiatric comorbidities the presence of psychotic symptoms was the only variable that differed between the suicidal and non-suicidal patients with ASD (Table 2).

Table I Suicidality risk factors of children and adolescents with autism spectrum disorder

\begin{tabular}{|c|c|c|c|}
\hline Characteristics & $\begin{array}{l}\text { Suicidal } \\
\text { group } \\
(\mathbf{N}=16)\end{array}$ & $\begin{array}{l}\text { Non-suicidal } \\
\text { group } \\
(\mathbf{N}=39)\end{array}$ & $P$-value \\
\hline Mean age, SD (years) & $13.4 \pm 2.0$ & $13.7 \pm 3.2$ & 0.67 \\
\hline Prepubertal:pubertal & $4: 12$ & $14: 25$ & 0.43 \\
\hline Male: female & $15: 1$ & $34: 5$ & 0.46 \\
\hline \multicolumn{4}{|l|}{ ASD subtypes } \\
\hline$A D$ & 7 & 17 & 0.89 \\
\hline AS & 8 & 18 & \\
\hline PDD-NOS & 1 & 4 & \\
\hline $\begin{array}{l}\text { Positive history of self } \\
\text { mutilation }\end{array}$ & 3 & 16 & 0.52 \\
\hline $\begin{array}{l}\text { Positive family history of } \\
\text { completed suicide }\end{array}$ & 3 & I & $0.002 *$ \\
\hline $\begin{array}{l}\text { Positive family history of lethal } \\
\text { and nonlethal suicidal behaviors }\end{array}$ & 6 & 4 & $0.026^{*}$ \\
\hline $\begin{array}{l}\text { Positive family history of } \\
\text { alcohol/substance use disorder }\end{array}$ & 1 & 7 & 0.25 \\
\hline Parental loss or divorce & 3 & 16 & 0.52 \\
\hline
\end{tabular}

Note: $* P<0.05$, statistically significant difference.

Abbreviations: ASD, autism spectrum disorder; AD, autistic disorder; AS, Asperger's syndrome; PDD-NOS, pervasive developmental disorder not otherwise specified; SD, standard deviation.
Table 2 Comparison of comorbid disorders between the suicidal group and non-suicidal group

\begin{tabular}{|c|c|c|c|}
\hline Comorbidity & $\begin{array}{l}\text { Suicidal } \\
\text { group } \\
(\mathrm{N}=16)\end{array}$ & $\begin{array}{l}\text { Non-suicidal } \\
\text { group } \\
(\mathbf{N}=39)\end{array}$ & $P$-value \\
\hline $\begin{array}{l}\text { Mean number of comorbid } \\
\text { disorders }\end{array}$ & 1.93 & 1.48 & 0.17 \\
\hline Mood disorders & $5(3 \mid \%)$ & $8(20.5 \%)$ & 0.30 \\
\hline Depression & $3(18.7 \%)$ & $7(18 \%)$ & 0.61 \\
\hline Bipolar & $2(12.5 \%)$ & I (2.5\%) & 0.20 \\
\hline Anxiety disorders & 7 (44\%) & $17(44 \%)$ & 0.61 \\
\hline Generalized anxiety disorder & I (6.2\%) & $2(5 \%)$ & \\
\hline Separation anxiety disorder & $0(0 \%)$ & I (2.5\%) & \\
\hline Obsessive compulsive disorder & $2(12.5 \%)$ & $8(20.5 \%)$ & \\
\hline Social phobia & I (6.2\%) & $2(5 \%)$ & \\
\hline Specific phobia & I (6.2\%) & $3(7.7 \%)$ & \\
\hline $\begin{array}{l}\text { Attention deficit hyperactivity } \\
\text { disorder }\end{array}$ & $8(50 \%)$ & $28(72 \%)$ & 0.11 \\
\hline Psychotic features & $4(25 \%)$ & I (2.6\%) & $0.02 *$ \\
\hline In mood disorder & $2(12.5 \%)$ & I (2.5\%) & \\
\hline In psychotic disorders & $2(12.5 \%)$ & $0(0 \%)$ & \\
\hline
\end{tabular}

Note: $* P<0.05$, statistically significant.

\section{Discussion}

This study investigated the rate and relevant risk factors of suicidality in high functioning children and adolescents with ASD. Comparing the ascertained suicidality rate of $29 \%$ in our study group with the result of previous studies implemented on a typically developing adolescent population in our country, the rate of suicidality in our group appears to be slightly higher than the rate in the general population in our society $(25.6 \%)$ and in the typically developing children with the same age range and socio-economical status $(25.77 \%){ }^{21,22}$ Notably, however, the rate of suicide attempts in our group $(12.7 \%)$ was higher than typically developing adolescents reported by Nock et al and Eskin who proved that the lifetime prevalence of suicide attempts is $4.1 \%$ in the United States and $4.5 \%$ in Turkey. ${ }^{8,21}$

Given that our study group was regularly followed-up and many of the individuals in our group took medication for their additional psychiatric disorders, the rate of suicide observed in our clinically referred population might well be even lower than the rate in individuals with no access to mental health services. It can be concluded that children and adolescents with high functioning ASD have a higher risk of suicide compared to their typically developing peers. The result of our study reconciles with results of previous studies which reported a high rate of suicidality in groups with a diagnosis of ASD. ${ }^{14-17}$

Referring to our observations regarding the type of suicidality highlighted above; it is evident that the type of suicidal behaviors and/or ideation shows a number of differences 
compared to typically developing individuals. In our group of 55 individuals, 16 of them were identified as suicidal. More specifically; seven of them had attempted suicide, six of them had considered suicide and three of them had made suicidal statements. Cassidy et al's study has reported that the rate for suicidal ideation is $66 \%$, and for suicidal plans or attempts is $35 \%$, in their adult population. ${ }^{12}$ The suicidality rate was higher than shown in our data; this may be as a result of the age of the population. Their participants were adults who might experience more social isolation, trauma and bullying and were more emotionally overwhelmed than our sample.

Suicidal thoughts and behaviors rate was reported as $11 \%$ in Storch et al's study in which youth with autism were more likely to have suicidal thoughts than ones with AS. ${ }^{15}$ Our data are inconsistent with this report. We did not observe any significant differences in suicidality between the AS and AD groups which might be a result of a high functioning population. Our group might have similar deficits in understanding the consequences of the negative results of suicide and events, therefore both groups had the same rate of suicidality. However, previous reports stated that in terms of rate of suicidality, the high functioning group did not differ from the low functioning group. ${ }^{14}$

There are mainly three types of suicidality: suicidal attempts, thoughts and declarations. Suicidal attempts are the most common clinically noticed form of suicidality. As opposed to the data obtained from the general population where drug poisoning is the most common type of attempt, individuals with ASD included in this group more commonly preferred the suicide method of jumping out of a window. ${ }^{21-24}$ From our contemporaneous analysis of our findings provided above, it is also notable that a number of bizarre ways of suicide attempts and plans were observed. In the light of limited evidence on this issue, one possible explanation is that the unusual self-harming behaviors in this group are attributable to impairment in abstract thinking.

Another fundamental point from our study was the variance in the risk factors associated with suicide in our study group. Our study was not able to identify any statistically significant differences between the suicidal and nonsuicidal group in variables such as age, gender, subtype of ASD, self-mutilative behavior, family history of substance abuse, parental loss, and divorce. Although there was no statistically significant difference in terms of age between the two groups, it was verified that the age of all suicidal patients was 11 years or older. This is materially consistent with previous studies regarding the higher risk of suicide in children older than $10 .^{8,14,24}$ As an exception, there was a statistically significant difference between the groups in terms of positive family history for attempted and completed suicide, however, this is consistent with data on trends in suicide studies related to typically developing individuals. ${ }^{25}$ Among all psychiatric comorbid conditions, only the presence of psychosis showed a statistically significant difference between our suicidal and non-suicidal groups. It was observed that our suicidal group was more severely exposed to psychotic symptoms than the non-suicidal group. In fact, in the whole group only five individuals had psychotic features and four out of those five individuals also had suicidality. This finding is consistent with recently published reviews which have reported a high rate of suicidality in patients with psychotic disorders. It has been reported that lifetime prevalence of lethal suicidal behaviors in schizophrenia varies from 5\% to $10 \%$. Young age is a well-known risk factor for suicide in this group. ${ }^{26}$ Psychotic feature in mood disorder is also regarded as one of the factors increasing the risk of suicidality. ${ }^{27}$ Therefore we have to be cautious regarding psychotic features observed in young patients. We observed an insignificant difference in depression rate between the suicidal (18.7\%) and nonsuicidal group (18\%) which is inconsistent with the previous data. ${ }^{12,15}$ Our study group was under medication which might have led to a smaller burden of depression and relieved the perceived distress.

Although the data obtained through our study group provided important information in respect of the main purpose and ambit of our research, our study suffers from a number of limitations. One important limitation is that our group only consisted of a clinically referred population under regular psychiatric follow-up; namely it does not represent all individuals with ASD. Absence of a control group with typically developing children to make a proper comparison is one of the most important limitations of our study. The measures used in this study were originally designed for typically developing individuals rather than individuals with ASD. This potential limitation was addressed by supplementing the data with clinical interviews. Another limitation is the lack of assessment for the potentially relevant risk factors of severity of ASD, peer victimization, bullying, and other traumatic events.

On the other hand, our study also has a number of strengths which are likely to increase the reliability of outcome of our analysis: we assessed a relatively younger population with ASD in the study group. We gathered data from both self and parent reports and clinical observations. 
In conclusion, although several methodological limitations were present, to our knowledge this study is the first research on suicidality in ASD individuals in a developing country, Turkey. Our study provides evidence that the rate of suicidal behavior in children and adolescents with ASD is higher than in a typically developing population. The type of suicidal behaviors is bizarre and different in this group. In addition, positive family history for suicide attempt, completed suicide, and presence of psychotic disorders could be considered as risk factors in the context of suicidality. By identifying risk factors in children and adolescents with ASD, early recognition of suicidality and prevention of its consequences is crucial. Generally, children with suicidal ideations do not ask for professional help, therefore all children with ASD should be screened for suicidality.

\section{Disclosure}

The authors report no conflicts of interest in this work. The authors have no financial interests related to the material in the manuscript.

\section{References}

1. American Psychiatric Association. Diagnostic and Statistical Manual of Mental Disorders 5th edition. Washington, DC: American Psychiatric Association; 2013.

2. Ghaziuddin M, Weidmer-Mikhail E, Ghaziuddin N. Comorbidity of Asperger syndrome: preliminary report. J Intellect Disabil Res. 1998; 42(Pt 4):279-283.

3. Leyfer OT, Folstein SE, Bacalman S, et al. Comorbid psychiatric disorders in children with autism: interview development and rates of disorders. J Autism Dev Disord. 2006;36(7):849-861.

4. Simonoff E, Pickles A, Charman T, Chandler S, Loucas T, Baird G. Psychiatric disorders in children with autism spectrum disorders: prevalence, comorbidity, and associated factors in a population-derived sample. J Am Acad Child Adolesc Psychiatry. 2008;47(8):921-929.

5. Mukaddes NM, Hergüner S, Tanidir C. Psychiatric disorders in individuals with high-functioning autism and Asperger's disorder: similarities and differences. World J Biol Psychiatry. 2010;11(8):964-971.

6. Bridge JA, Goldstein TR, Brent DA. Adolescent suicide and suicidal behavior. J Child Psychol Psychiatry. 2006;47(3-4):372-394.

7. Hawton K, Saunders KE, O'Connor RC. Self-harm and suicide in adolescents. Lancet. 2012;379(9834):2373-2382.

8. Nock MK, Green J, Hwang I, et al. Prevalence, correlates, and treatment of lifetime suicidal behavior among adolescents: results from the National Comorbidity Survey Replication Adolescent Supplement. JAMA Psychiatry. 2013;70(3):300-310.

9. Hardan A, Stahl R. Suicidal behavior in children and adolescents with developmental disorders. Res Dev Disabil. 1999;20(4):287-296.
10. Mandell DS, Walrath CM, Manteuffel B, Sgro G, Pinto-Martin JA. The prevalence and correlates of abuse among children with autism served in comprehensive community-based mental health settings. Child Abuse Negl. 2005;29(12):1359-1372.

11. Mukaddes NM, Fateh R. High rates of psychiatric comorbidity in individuals with Asperger's disorder. World J Biol Psychiatry. 2010; 11(2 Pt 2):486-492.

12. Cassidy S, Bradley P, Robinson J, Allison C, McHugh M, BaronCohen S. Suicidal ideation and suicide plans or attempts in adults with Asperger's syndrome attending a specialist diagnostic clinic: a clinical cohort study. Lancet Psychiatry. 2014;1(2):142-147.

13. Kato K, Mikami K, Akama F, et al. Clinical features of suicide attempts in adults with autism spectrum disorders. Gen Hosp Psychiatry. 2013; 35(1):50-53.

14. Mayes SD, Gorman AA, Hillwig-Garcia J, Syed E. Suicide ideation and attempts in children with autism. Research in Autism Spectrum Disorders. 2013;7(1):109-119.

15. Storch EA, Sulkowski ML, Nadeau J, et al. The phenomenology and clinical correlates of suicidal thoughts and behaviors in youth with autism spectrum disorders. J Autism Dev Disord. 2013;43(10):2450-2459.

16. Hannan G, Taylor E. Suicidal behavior in adolescents and young adults with ASD: findings from a systematic review. Clin Psychol Rev. 2013;33(8):1197-1204.

17. Segers M, Rawana J. What do we know about suicidality in autism spectrum disorders? A systematic review. Autism Res. 2014;7(4): 507-521.

18. American Psychiatric Association. Diagnostic and Statistical Manual of Mental Disorders Fourth edition Text Revised. Washington, DC: American Psychiatric Association; 2000.

19. Kaufman J, Birmaher B, Brent D, et al. Schedule for Affective Disorders and Schizophrenia for School-Age Children-Present and Lifetime Version (K-SADS-PL): initial reliability and validity data. $J$ Am Acad Child Adoles Psychiatry. 1997;36(7):980-988.

20. Gokler B, Unal F, Pehlivanturk B, Cengel Kultur E, Akdemir D, Taner Y. Reliability and Validity of Schedule for Affective Disorders and Schizophrenia for School Age Children-Present and Lifetime Version-Turkish Version (K-SADS-PL-T). Turk J Child Adolesc Ment Health. 2004;11(3):109-116.

21. Eskin M. Suicidal behavior as related to social support and assertiveness among Swedish and Turkish high school students: a cross-cultural investigation. J Clin Psychol. 1995;51(2):158-172.

22. Dalkilic A, Burakgazi Yilmaz H, Unlu A, Evcin U, Prajapati P, Pumariega A. Risk factors for suicidal ideation among high school students in Istanbul. Adolesc Psych. 2013;3(1):102-113.

23. Mościcki EK. Epidemiology of completed and attempted suicide: toward a framework for prevention. Clin Neurosci Res. 2001;1(5):310-323.

24. Mościcki EK. Identification of suicide risk factors using epidemiologic studies. Psychiatr Clin North Am. 1997;20(3):499-517.

25. Hamdan S, Melhem N, Orbach I, et al. Risk factors for suicide attempt in an Arab kindred. J Affect Dis. 2011;132(1-2):247-253.

26. Hor K, Taylor M. Suicide and schizophrenia: a systematic review of rates and risk factors. J Psychopharmacol. 2010;24(4 Suppl):81-90.

27. Caetano SC, Olvera RL, Hunter K, et al. Association of psychosis with suicidality in pediatric bipolar I, II and bipolar NOS patients. $J$ Affect Dis. 2006;91(1):33-37.
Neuropsychiatric Disease and Treatment

\section{Publish your work in this journal}

Neuropsychiatric Disease and Treatment is an international, peerreviewed journal of clinical therapeutics and pharmacology focusing on concise rapid reporting of clinical or pre-clinical studies on a range of neuropsychiatric and neurological disorders. This journal is indexed on PubMed Central, the 'PsycINFO' database and CAS,

\section{Dovepress}

and is the official journal of The International Neuropsychiatric Association (INA). The manuscript management system is completely online and includes a very quick and fair peer-review system, which is all easy to use. Visit http://www.dovepress.com/testimonials.php to read real quotes from published authors. 